\title{
Engaging students in online workshops using Articulate Rise
}

\section{Zara Hooley}

De Montfort University

\section{Emily Forster}

De Montfort University

\section{Andrew Browne}

University of Strathclyde

Keywords: learning development; online delivery; interactive workshop; academic writing; statistics support; Articulate Rise; Covid-19.

\section{The challenge}

In this paper we discuss our experiences of teaching interactive, in-curriculum learning development sessions on statistics and academic writing. During the transition to online learning prompted by the pandemic, our challenge was how to replicate the interactive, participatory activities that would normally occur in a face-to-face session. In online sessions, many questions seemed to go unasked, and only one or two students verbally participated. As a result of this, many of our group activities were not immediately transferable to the online environment.

\section{The response}

We needed to create more opportunities for students to participate in 'learning by doing' (Race, 2014), as students are more likely to learn if they are actively engaged in the session. We wanted to maintain peer-to-peer work where possible, due to the clear learning benefits (Tullis and Goldstone, 2020). In addition, we wanted to make the most of the online environment. We therefore needed to find a simple, sharable vehicle for housing 
content, presenting on screen, and creating interactive activities while encouraging peerto-peer work.

Articulate Rise is software designed to create online courses. It enabled us to use varied ways of presenting information - prose, bullet points, images, videos and labelled graphics (see Figure 1). We were thereby able to replicate face-to-face activities including card sorting activities, flip cards, and quizzes. It is an online tool, which made it easy to access anywhere, and we could share courses we had created with other members of the team to promote collaboration. The platform is designed for asynchronous delivery. However, we used it as a synchronous activity tool. An advantage is how easy it is to create activities such as flashcards and labelled graphics, and you can embed videos.

Figure 1. Creating a course using blocks.

\begin{tabular}{|c|c|c|c|c|c|c|c|c|c|}
\hline 浀 & 团 & $\vdots \equiv$ & 国 & {[} & ‘国, & 吅 & 品 & $C^{\circ}$ & $\mp$ \\
\hline $\begin{array}{c}\text { All } \\
\text { Blocks }\end{array}$ & Text & List & Image & Video & Process & Flashcards & Sorting & Labeled Graphic & Continue \\
\hline
\end{tabular}

To lead the sessions, we screen-shared our version of the materials through Microsoft Teams. We also shared a weblink to the published course allowing students to open their own version in an additional window. Throughout the workshop, students were asked to switch to their own screen and participate in the activities, and then return to the group screen and contribute to the group discussion verbally or in chat. Following this we would then model an example or discuss the feedback.

During statistics teaching, we found that giving students the opportunity to practise solving the problems embedded in the Rise course before they were asked to share their ideas promoted participation (DeVaney, 2010). More students contributed when we ran the session this way, compared to when we delivered it using PowerPoint. The provision of a series of short activities, which included card sorting activities, flip cards, and quizzes, allowed us to pace the session well and oversee activities to keep students on task (Utts et al., 2003; Mills and Raju, 2011). 
In our face-to-face academic writing classes, we had previously used card sequencing activities for students to order their writing process, and they would complete this activity in small groups. The discussion between the students as they moved the cards around and justified their position, was often the most useful part of the activity. It gave us the opportunity to hear what the students thought about writing as they reflected on the process.

Articulate Rise allowed us to replicate this exercise and retain the valuable discussion (see Figure 2), albeit after the student had completed the sequence. One issue was that Rise enables a sequencing activity, but with only a 'right or wrong' answer. We overcame this by using the rubric to explain that there were no right or wrong answers and that we were more interested in how students justified their choices. We would issue the activity link and then ask students to write the word 'done' in the chat box when they had completed the activity. We would then move them into smaller breakout rooms and ask them to discuss their process. Before moving them, we posed a few key questions such as 'do you think essay writing really is a linear process?'.

\section{Figure 2. Card sorting activity.}
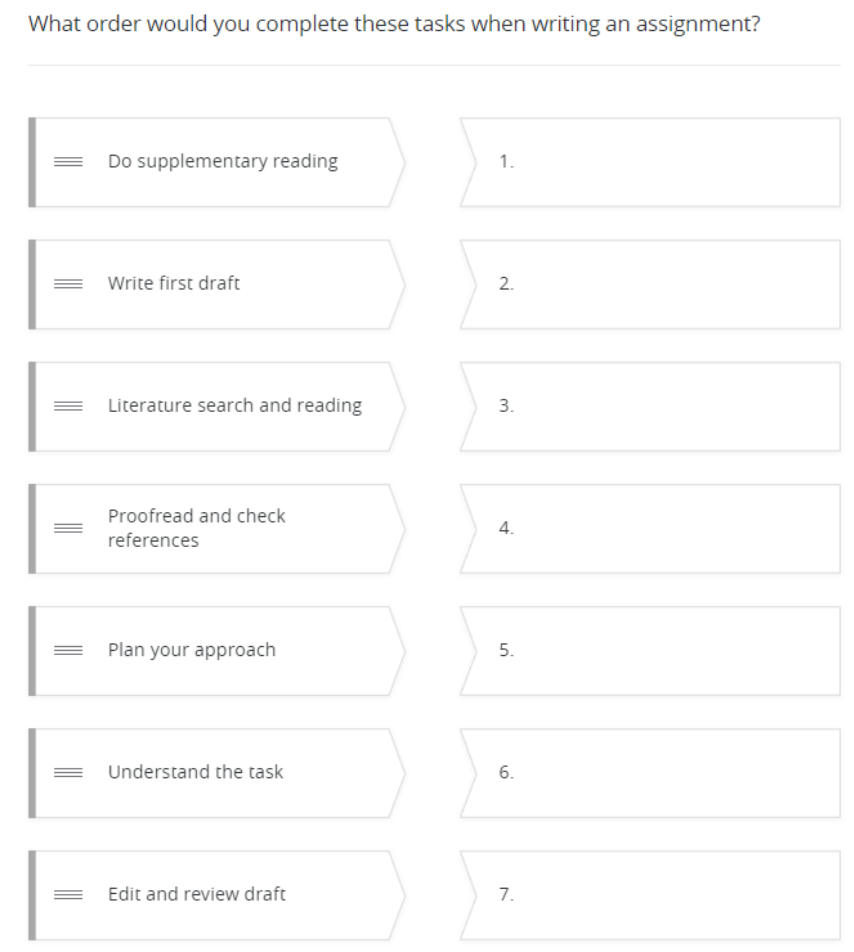
In the breakout rooms, the students discussed the questions, but often used the chat box function rather than turning cameras and microphones on. After this, we would move them back to the main room and model a writing process, posing reflective questions throughout, and asking for comments in the chat box. The discussions that took place in the breakout rooms did not reach the same depth as those we had observed live in the pre-Covid environment but were still useful.

Sessions on academic writing are often more effective if they directly relate to the specific assignment that students are currently working on. When students are learning online, they have access to the internet and their devices during the session. In a session on writing your first essay at university, we decided to use this as a positive feature of the session and got students to actively make a start on their assignment to maximise the relevance of the session.

We had previously published a number of web based study skills guides in Articulate Rise on topics such as essay writing. These had resources such as an essay planning template as well as quizzes and activities. The session ran in the form of an online 'treasure hunt', which took the students through the process of planning and writing, with them periodically going to find resources that would help them with their assignment. The aim was to help them learn how to navigate the library website and to provide them with standalone resources that they could access for further guidance when they were working independently (including two Articulate Rise resources).

On reflection, getting students to look for the resources themselves worked well as they were helping each other in the chat, finding the resources together and supporting one another

\section{Recommendations}

It was possible to replicate some of the interactivity and peer-to-peer support in our faceto-face teaching through the use of the sharable resources we created in Rise, but we found that interaction needs to be more structured and supported than it would be in a 
face-to-face session. Giving students the chance to participate in activities in real time, and then to discuss them together, did improve participation in the online sessions. A possible improvement we could implement in the future would be to allow students more control over how they interact, for example by introducing breakout rooms defined by communication preference: Room 1 = microphone on, Room 2 = chat only. Using a technique like this, which works with students' preferences, could lead to a more comfortable and open discussion.

Our key advice is this: make the most of the online format by including things you might not be able to do in a face-to-face session. The online environment opens up a range of immediate resources for learning activities. The creation of the courses also provides the students with a resource they could return to in an asynchronous manner, in order to support their learning outside the session.

\section{References}

DeVaney, T.A., (2010) 'Anxiety and attitude of graduate students in on-campus vs. online statistics courses', Journal of Statistics Education, 18(1). Available at: https://doi.org/10.1080/10691898.2010.11889472 (Accessed: 21 October 2021).

Gewin, V. (2020) 'Into the digital classroom', Nature, 580, no. 7802, pp.295-296. Available at: https://media.nature.com/original/magazine-assets/d41586-020-008967/d41586-020-00896-7.pdf (Accessed: 21 October 2021).

Mills, J.D. and Raju, D. (2011) 'Teaching statistics online: a decade's review of the literature about what works', Journal of Statistics Education, 19(2). Available at: https://doi.org/10.1080/10691898.2011.11889613 (Accessed: 21 October 2021).

Race, P. (2014) Making learning happen: a guide for post-compulsory education. $3^{\text {rd }}$ edn. London, Sage. 
Tullis, J.G. and Goldstone, R.L. (2020) 'Why does peer instruction benefit student learning?', Cognitive Research, 5(15). Available at: https://doi.org/10.1186/s41235020-00218-5 (Accessed: 21 October 2021).

Utts, J., Sommer, B., Acredolo, C. Maher, M.W. and Matthews, H.R. (2003) 'A study comparing traditional and hybrid internet-based instruction in introductory statistics classes', Journal of Statistics Education, 11(3). Available at: https://doi.org/10.1080/10691898.2003.11910722 (Accessed: 21 October 2021).

\section{Author details}

Zara Hooley is a Senior Lecturer in Learning Development at De Montfort University.

Emily Forster is a Senior Lecturer in Learning Development at De Montfort University.

Andrew Browne was a Lecturer in Statistics at De Montfort University. He is now a Teaching Fellow in Statistics at the University of Strathclyde. 